\title{
ICTs based Physics Learning
}

http://dx.doi.org/10.3991/ijep.v6i3.5899

\author{
Athanasios S. Drigas, and Maria-Theofania L. Kontopoulou \\ NCSR DEMOKRITOS, Institute of Informatics and Telecommunications, Net Media Lab, Athens, Greece
}

\begin{abstract}
In this paper we concentrate on the implementation and the results of teaching and learning methods which are based on use of Information and Communication Technologies (ICTs) for understanding of Physics concepts. These methods are simulations, virtual reality, video games and were used to students of all levels, from elementary school to university for undergraduates and postgraduates students. Also these methods include a wide representative range of Physics` branches.
\end{abstract}

Index Terms-Physics education, ICTs, simulations, virtual reality, learning games.

\section{INTRODUCTION}

In Physics we represent information using words, equations, graphs, diagrams, and so on in order to observe and describe a physical system. But many students find it difficult to create these representations and yet they don't understand how the representation express information for the system and how they are related to each other [8]. The essential pedagogical problem from high school to the university is that the students have great difficulty to apply the physics theory and equations to the phenomena that they observe in the lab or in the everyday world [11]. A big problem that exists is that learners have their own ideas and interpretations of natural phenomena based on their daily experience and language that prevents them to assimilate scientific models that are necessary to correctly understand the scientific concepts [3]. The studies show that learning is possible when it occurs in contexts that are culturally, linguistically, and cognitively meaningful and relevant to students. Learning is a cultural process even within a single class [23]. The experiences which are gained by the students in a classroom affect their attitudes and beliefs about the physics and learning physics [5].

The curricula of most countries focus on breadth than in depth of scientific knowledge and thus do not provide adequate opportunity for inquiry-related learning But international and national science standards call for inquiry learning and a focus on depth of understanding [23]. Inquiry-based learning is the dominant factor that leads to good science education [30]. The deeper understanding of scientific knowledge and the practice of Science requires from students to be engaged in doing science, in the practices and methods related to science-inthe-making used by scientists instead of just focusing on learning about science, that is just learning the established results of science [30]. In inquiry learning, students learn through exploration and application of scientific reasoning. It has been found to be among the most effective methods for acquiring conceptual knowledge [13].

Should also be noted that many of the experiments that helps learners to understand the concepts of physics cannot be performed in real laboratories because it is impos- sible to be conducted because they are very dangerous, very complex, take a long time [9] or they are too expensive.

Students must therefore be provided with motivation and encouragement during the teaching and learning process for conceptual change [9]. It is necessary a more exciting experience for them [26].

Computers are the most popular tool of youth so their use as a learning tool is a very positive step [26].The recent years the use of Information and Communication Technology for teaching science has increased significantly and is an effective tool for teaching, practical activities and research [15]. In this paper we will deal with simulations virtual reality and video games as teaching methods based on Information and Communication Technology.

With the help of simulations students study in a little time various scientific phenomena using several presentation methods such as pictures, graphs, vectors, etc. [9]. Also they may alter the variables, create alternative scenarios, receive immediate feedback, observe the results and puts their own conclusions [9]. So the curiosity of learners is caused. Surveys have shown that students learn better when they themselves have the control [8]. They can explore the relationships between different quantities [14] and connect multiple representations even hardly visible in the real world [4]. They acquire knowledge in abstract concepts leading to better mental models and are involved actively in their learning [10]. Also experiments that are difficult to be conducted or difficult for students to understand them in real laboratory are becoming more simply by simulations. In this way the learning of physics gets fun and exciting, event that affects the view of students for physics and encourage them [5]. So the simulations are very important tool for science learning activities, especially in activity-based scientific inquiry and in conceptual development in science [9].

According to recent research when students participate in experimental guided-inquiry activities by using virtual reality earn a deeper understanding of scientific concepts [12]. Virtual environments are using the third dimension to create the sense of reality to the participant and provide the illusion of immersion in a space of three dimensions in which the user can carry out actions similar to those that can make if he is in a real environment [11]. For these environments computers are used and everything is occurring in real time [17]. Virtual reality is a, multi-sensory, mental and motor experience which is based on interaction, immersion and navigation [16]. by using computer graphics, sounds, and images to reproduce electronic versions of real-life situations [17] these experiences are considered, for many users as extremely interesting and attractive [16]. Students try different options without running the risk, costs.Also it takes less time than that in real laboratory [17]. One may also try out various space- 
temporal situations that are actually impossible to do in real world and that instigate its imagination and creativity and extend its knowledge The virtual world appears as canonic sort of the cyber-culture [16]. Virtual worlds provide hands-on learning experiences using the mouse of computer and so make easier yet the understanding of abstract physics concepts [11]. Users interact not only with objects but also with other users enhancing collaborative learning [11].

Digital games can offer in depth understanding of scientific concepts with inquiry learning and even by inquiry -based appealing manner. These games help students to explore demanding concepts emphasizing research process and not to mechanically learning that most of Traditional Teaching Methods use .In 2006 Federation of American Scientists in a report said that digital games is a great new tool for education prompting governmental and private organizational support to fund research into the application of complex gaming environments for learning (FAS, 2006). In 2009, a special issue of Science did the same proposal [23]. The well-designed games, are challenging, provide immediate feedback, the player participate actively [22] develop plans and strategies, observe their results. They can take risks, can make mistakes with minimal implications and learn from them. We identify cognitive strategies which used by players during the course of the game that portray and require predictions of accurate scientific phenomenon and thus we can create a new type of evaluation of the learning of science [22]. Learners acquire ways of thinking about the scientific world, based on experiences from game worlds using intuitive understandings that they developed in game worlds in order to interpret physics problems [21]. So they will be able to assimilate abstract concepts and interpret phenomena that are difficult to understand [30].

\section{Simulations}

Aleksandrova and Nacheva used web based technology for teaching of electromagnetic phenomena. Web pages were created by Microsoft FrontPage, ArcSoft Photostudio 5.5 and Microsoft Photo Editor. Students used computer simulations which was Java applets, video clips and movies with exceptional optical effect. In the case of "Charge particle in magnetic field" they proved the motion of charge particle with different sign and specific charge. In the case of "Hall effect" they investigated the dependence between intensity of Hall electric field and applied magnetic field. After they conducted the real experiments and managed to explore abstract and theoretical concepts combining simulations and real experiments [1].

Ferlin et al invented a data acquisition hardware and interactive software were developed in Computer Engineering Laboratories at UnicenP, with the help of which students carried out mechanical physics experiment. In the first research a pendulum which performs dumped oscillations and in the second they used an air track and an impact transducer in order to corroborate the conservation of linear momentum. The innovation is that students performed a computer simulation and after they conducted a real computer-assisted experiment in a physics lab. So students could in real time to obtain values of physical quantities like velocity and acceleration .Also the realtime graphics help students to detect the difference between position graphic and real mobile trajectory [2].
Farrokhnia and Esmailpour disunited randomly 100 undergraduate students into three groups in order to study DC electric circuits. The real group conducted the real experiment, the virtual used computer-based simulation, the comprehensive combined simulation with real lab equipment. For simulations used Circuit Construction Kit (CCK) simulation software Also were used diagnostic instrument, Determining and Interpreting Resistive Electric circuits Concepts Test. At the end all students asked to construct the real circuit to measure required quantities and respond to related questions. So was found that virtual team built fast the requisite circuit and had more correct answers. In second place was comprehensive team [3].

Kohnle et al. carried out observation sessions with second year students from University for an introductory course in quantum mechanics. The learning process included online texts, simulations and related activities. Each simulation had the Simulation view with introductory text and interactive controls and the Step-by-step Exploration view that allows the user to step through detailed text explanations with animated highlighting Two of these simulations was homework for students of another University. The results showed that the optimization of the simulation controls leads to quick data collection and so students could compare easy experimental values and theoretical predictions and understand their connection .Also with the activities students made direct connections between mathematical and visual representations [4].

Bozkurt and Ilik used interactive computer simulations for the students of physics and science departments while for students of chemistry and computer departments they used traditional teaching methods for study of Physics 1(Mechanics) at University. PHET group created Java and Flash simulations. From ANOVA analysis of pre and posttests was observed much higher progress to simulation group. For measuring students beliefs about physics and learning physics was used The Colorado Learning Attitudes about Science Survey which showed that simulation group had positive crease for all sub-dimensions on their beliefs after application while the other group had decrease to some sub-dimensions [5].

Zacharia and Anderson researched the effects of computer simulations on prospective teachers' physics conceptual understanding of mechanics, waves /optics and thermal physics .Researchers made an experimental and a control group. There was an introductory experience for two groups through a link on Website. The experimental group used the simulation in addition which was chosen from the available on Web. Both of the groups conducted the same experiments which were selected from the Physics by Inquiry Curriculum and the Tutorials in Introductory Physics. Afterwards conceptual tests and interviews were used. The results showed that the combination of real experiment and simulation increased the ability of students to make valid scientific predictions and give scientifically accepted explanations related to physical phenomena in experiments [6].

Podolefsky et al. interviewed two non-science graduate students and two students who were undergraduates enrolled in Light and Color, a course for non-science majors. Researchers founded substantially similar results for both of them. Students had the chance to choose from 12 high interactive PHET simulations without other instruction how to procced or use them, for answering questions from Force Concept Inventory. Questions were for Projectile 
and Circular motion and Horizontal Force. Results showed that in total students' sim choices were about the same. In general students used the simulations productively to answer FCI questions By using sims they explored and learned science contents without the guidance. They recreated problem situations exactly and made deeper structural connections after using simulations [7].

Aravind and Heard used a web based freely available simulation published by McGraw-Hill in combination with lecture for the effect of friction in body movement which is traveling down a banked circular road .Before sim students had taken lectures from textbook "Physics" by Cutnell and Johnson for learning to draw free body force diagrams The students were from freshmen to senior undergraduates and also they came from the field of chemistry, biology, geology, etc. They had known physics only from high school. After sim and lecture they solved a conceptual problem. The majority of students solved the problem correctly. This means that this way of teaching can significantly enhance students' understanding of physics concepts [8].

Kroothkaew and Srisawasdi selected secondary-school students aged between 17 and 18 to learn for light refraction. They had basic computer information and communication technology experience but they hadn't used computer physics simulations. For this study were used PHET simulations which provided to students visualizations of the refraction of light phenomenon. Also were used a dual-situated learning model (DSLM).Were conducted quantitative analysis of method's effects using a Friedman test and a Wilcoxon sign-ranked test and qualitative analysis based on She and Liao's ideas. The results from pretests, post-tests and a retention tests showed that from the combination of simulations and DSLM students developed conceptual change namely they repaired their alternative conceptions into scientific conceptions and so they were led to conceptual understanding of light refraction [9].

Junglas applied simulation programs for thermodynamics' teaching to engineering students. He used four of many thermodynamics applets from homepage of the PhysBeans project in and in the forthcoming new edition of and which were based on the JavaBeans model. .Those programs were Program StateChange, Program FirstLaw Program Stirling, Program Isex. Students got qualitative understanding of thermodynamic processes, understood what is enthalpy entropy, direction of energy flows and their use to technically relevant applications ,studied exact curves and analyzed complex systems. Thus they participated actively in the lectures, checked the results of homework exercises and improved their access to the final exams [10].

\section{VIRTUAL REALITY}

Scheucher et al.analyzed 3D collaborative virtual learning enviroments(CVLE) applied for the "Force on a dipole". The experiment developed at MIT combines an interactive lab (iLab) with the TEALsim(Technology Enabled Active Learning) java3D simulation toolkit in Project Wonderland,Sun's toolkit for creating collaborative 3D virtual worlds. The combination of these projects provides a powerful tool for students in order to view a synchronized visualization that is an accurate representation of the invisible electromagnetic fields and give the opportunity for teachers and students to work together as avatars as they control actual equipment, and analyze the results across the world [11].

Taramopoulos et al. used a sample of 16 students of the third grade of junior high school who had not deal with the design of experiments. They applied the 3-dimensional virtual reality electric circuit laboratory of the Open Learning and Laboratory Environment (OLLE).After instruction the students were examined in a post-test that included two assessment tasks of measuring the unknown resistance of two electric devices of OLLE in order to evaluate their ability to design and conduct of experiments in the field of electric circuits .Results show that participants got the ability to design and perform simple experiments with best progress in circuitry construction indicating a high level of familiarity with visual equipment [12].

Kolloffel and de Jong dealt with students from secondary vocational engineering education. In 20 of them was done traditional instruction with the support extra inquiry learning in a virtual lab (virtual condition) and in 23 traditional instruction plus computer-based practice (traditional condition). The experiments included DC circuits, Ohms and Kirchhoff's Laws. In virtual condition used SIMQUEST authoring software. Presented photographic images of real equipment and students added or subtracted electrical components, regulated the voltage and measured voltages and currents. So they recognized the key concepts of quantities and the relationships between them and could solve complex conceptual and procedural problems but students in traditional condition had many difficulties [13].

Chen et al. applied to elementary school students a desktop virtual reality earth motion system (DVREMS) in order to clarify their unclear conceptions about Earth motion concepts like the shape and size of the Earth, the cause of the day/night cycle, the cause of the seasons and the length of daytime. For DVREMS used Microsoft $\AA$ Visual $\mathrm{C}++6$, with OpenGL as the 3D API .The students was browsing in a virtual environment by taking information from the system and learning the handling virtual objects. So they perceived and analyzed the concepts of astronomy faster and clearer .Of course it must be implemented to improve the DVREMS for adequacy of information and manipulation of virtual objects [14].

Logofatu et al. applied a data acquisition system (DAQ system) to ODL (Open Distance Learning) students of the Department CREDIS of University of Bucharest for the study of electrical and mechanical oscillations. They used DAQPad 6020E - data acquisition board, Graphical programming language LabVIEW a software for creating virtual instruments (oscilloscopes, waveform generator, digital multimeter etc.), FD4E signal generator, capacitors, coils, resistors, etc. The users could create or modify virtual instruments with great flexibility and in little time so as to analyze and present the experimental data with a lot less errors than those made in real experiments [15].

Silva et al. presented an educational software by using virtual reality (VRML and JavaScript computational languages), with twenty-six physics experiments (e.g., Newton's laws) for high school. Software contains graphic organizers and concept maps. VRML was used for concept maps which were made using a HTML language. Physicists, Electrical Engineers, Instructional Designer created the software and hardware of virtual experiments and Visual Artist solved the different aesthetic questions 
PAPER

ICTS BASED PHYSICS LEARNING

by Low-poly technique Students could insert the data at the panel control or manipulate directly the disposable objects. The collaboration of multidisciplinary team was successful because students adapted, had easy access to the functions of system, used it easy, understood the terms of software and screen's icons, took many information, controlled and trusted the activities of system [16].

Yun et al. analyzed a virtual educational environment to studying abstract concept relative motion. For virtual objects used OPENGL as well as 3DMAX's modeling function. For reference scene used VRML 2.0.and for Control the Motion of Viewpoint used VRML by viewpoint node. Middle school students studied Relative Static, Relative Motion Relative Curvilinear and Relative Accelerated Motion. Results showed that by changing viewpoint to the observation of objects they understood relative motion. Also VR helped users to understand relative motion for cases to which they could not be experimented actually like a top moving on the North Pole [17].

McGrath et al .used the Real Time Relativity (RTR) a virtual reality software that was accompanied by instructional material and teachers' guidance for students of two third-degree research-intensive institutions with aim to understand special relativity Users utilizing personal computer with programmable graphics card experienced the effects of travelling at near light speeds participating in a game-like world with control over their motion and direction of view using clocks ,planets and abstract shapes .Students spent pleasantly with RTR. By development of visual models of the effects of special relativity they understood this concept that they found abstract before use RTR [18].

Lee et al. investigated the usefulness of IVRS (Immersive Virtual Reality System) to understanding of basic astronomical concepts like solar system ,earth moon relation etc. for middle school or college of general education applying that to undergraduate students IVRS is a VSS( virtual solar system) program that uses high resolution spacecraft images from NASA of systems planetary objects .Users supposedly that was astronomers who was flying in 3D astronomical Space .For IVRS used VRML language and 3D surround sound system. Results showed that IVRS is a very useful teaching method especially for understanding of spatiotemporal concepts such as astronomic definitions [19].

Demaree et al. described the implementation of Virtual Reality labs for improving of understanding of mechanics compared to traditional labs .At Ohio State University was developed a VR software for linear motion ,circular motion and collisions Users could regulate all parameters and they had to apply external forces to objects using a touchsensitive joystick. Students who did VR labs had high scores on FCI( Force Concept Inventory) questions which most related to the VR activities and responded that by using of joystick they understood better how forces affects motion While some students preferred the VR labs and some preferred the traditional labs was evidenced that the best is making mix both of them [20].

\section{LEARNING GAMES}

Squire et al .applied Supercharged to students (experimental group) of different nationalities in Chamberlain middle school. Supercharged is an electromagnetism simulation-computer game developed in consultation with
MIT physicist John Belcher. Players explored electromagnetic mazes, placing charged particles and controlling a ship which by altering its charge. They used representations of electric fields in the game and intuited some electrostatic concepts which they used as tool for solving problems, but they didn't conclude the complex concepts depicted in the game. The results showed that the games should have various levels so as to cause the students' interest and at the same time to do them exploratory players learn so Physics through the activities of the game. Teachers must focus student's attention and guide the class through the cooperative gameplay [21].

Asbell-Clarke et al. demonstrated the usefulness of game Impulse which developed by EdGE on the tacit understanding of Newtonian motion. For game-based assessment they used an Evidence Centered Design (ECD) framework. High school students in the U.S. Northeast who were recorded with Silverback software navigated their own ball to a moving goal, while avoiding collisions with an increasing numbers of ambient balls each new more difficult level predicting the motion of the balls around them. All of the balls motion obeys Newton's laws of motion and gravitation. From the video observation, think-alouds, and interviews identified the cognitive strategies that they believe that it originates from learners strategic moves within log data from Impulse. Strategic moves will then be used as the basis for using data mining to create prediction models which can automatically infer learners' strategies without requiring intensive hand coding of data. To investigate better cognitive strategies we can use regression models and Bayesian Knowledge Tracing [22].

Clark et al. built within the Unity 3D game engine and applied to students from high schools of Taiwan and USA a conceptually-integrated game called SURGE who played the game as the character Surge, a smart and brave female alien, who might save the adorable Fuzzies from the evil Emperor Hooke by applying principles of NEWTONIAN mechanics .For the tests which based on the Force Concept Inventory used in Taiwan the surveymonkey.com. and in USA the SURGE software environment . Tests showed that three of the assessment items with the biggest learning gains are similar both of the countries that indicates a fundamental match between the way the students engage and reflect on the principles of physics and the manner in which these principles are assessed regardless of cultural context .Written survey ,interviews and observations showed that the majority of pupils found the game enjoyable, interesting and that it helped them to understand the physics concepts .So conceptually-integrated games like SURGE can teach science concepts regardless of the cultural context of pupils [23].

Stapletonn and Taylor designed a computer game for conceptual understanding of physics of special relativity. Players are wandering into deep space on spacestation SRvoyager because of the malfunctioning navicomputer and taking the role of spacestation captain Log is being called to override manually the problem by playing simulations and solving puzzles in order to return the station to Earth orbit. Learners record Log`s experiences explain in writing the simulations and puzzles and "quick start" guides to their operation .So they are converted from learners-passive to generators of knowledge and gains new ways of thinking for understanding of science theory [24]. 
Pittman asked from his students of high school, LEAD Academy to use the virtual world of Valve software's commercial video game Portal 2 Puzzle Maker that run on Valve's Source engine to computers which has access to Valve's content distribution program, Steam for understanding physics concepts like friction, gravity, forces, momentum, energy. The player using only the portal gun Aperture Science Handheld Portal Device as a test subject from the first-person perspective had to navigate through a series of increasingly challenging experiments known as "test chambers." which consist of modular rooms with an entrance and an exit. Upon entering a room, the player must find, open, and reach an exit. Students to the exams built levels in puzzle Maker that demonstrated concepts which they learned, they described in writing the said concepts and explained how their levels demonstrated them. Students used Puzzle Maker as a laboratory tool to build and analyze virtual experiments that followed realworld laws of physics [25].

Carr and Bossomaier designed Relativistic Asteroids (RA) video game that incorporates features of special relativity and is implemented in $\mathrm{C}++$ for Microsoft Windows operating systems and uses the Microsoft DirectX 9.0c API for graphics calls .Participated subjects new to relativity from Australian Higher School Certificate (HSC) and Charles Sturt University (CSU) and subjects with prior classroom exposure from HSC. Player meanders a spaceship shooting and destroying drifting asteroids, while avoiding collision with the fragments. Data was analyzed using SPSS, and Microsoft Excel with programmed formulae. Scores of knowledge tests were analyzed using a Wilcoxon signed-rank test for non-normally distributed paired .Results showed significant effects on the new learners, although the improvements were significant for both of groups The game was accessible and interesting for learners [26].

Johnson and Mayer designed a 10-level puzzle game called Circuit Game for understanding of electric circuits. The participants were college students recruited from the Psychology Subject Pool at the University of California, Santa Barbara who divided into two groups and used 5 iMac computers with 17 in screens and 5 Cyber Acoustics headphones They had a problem situation and might click on a choice, drag and drop a circuit component into an existing circuit in order to accomplish some goal, or type a number into a box On levels 1-9 the selection selfexplanation group selected the reason for each move from an onscreen list while the generation self-explanation group might to type the reason for each move in an onscreen text box. The first group performed better on an embedded transfer test (i.e., level 10) on which applied what was learned about how circuits work to new kinds of problems [27].

Holbert and Wilensky designed and applied to children 7-13 years old the racing videogame FormulaT Racing. FTR uses Nitendo Wiimote a motion controller which has motion sensing capability and allows the player to control his car on screen by continuous adjustments of acceleration and heading via gesture recognition and pointing through multiple accelameters. FTR uses tailored representations of kinematics and new means of interacting with the player vehicle. Provide to player powerful constructive tools to which can implement his plans and debug them if his car fail. So he uses complex computational strategies and manages to encode the embedded kinematic concepts [28].

Masson et al used students 11 to 15 years old. One group played the arcade-style game, Enigmo and changed the realistic trajectories which followed principles of Newtonian mechanics for falling droplets in order to land in target receptacles. Another group played a strategy game, Railroad Tycoon 3, which aimed in building a simulated railway enterprise for students. After they were taught directly Newtonian Mechanics by PowerPoint slides The tests by ANOVA showed that only Enigma players improved and only to understanding of general parabolic shape of object trajectories but they didn't change the naive conceptions or misconceptions so that understand the objects motion .Both groups benefited about equally from tutorial .The ideal Enigma must involve interpretive information or instructional assistance [29].

Lee and Chee investigated the Centauri Learning Program in which high school students collaboratively understood the behavior of charged particles in electric and magnetic fields playing 3D game Escape from Centauri 7 that portray a sci-fi world They was explorers who crashlanded on a desert planet and might guide charged particles emitted by alien transmitters in order to emit emergency signal so escape. An Exploration Log assisted to understanding of phenomena. Force Concept Inventory used for tests and showed students improvement. Because of missing coordination of perception-conception of information from the game and the log and the actions associated with scientific research there were no productive talks and observed limited understanding of phenomena. The design of such curriculum learning must focus on promoting productive talks for better learning [30].

\section{CONCLUSION}

The use of computers nowadays is an integral part of everyday life of young people but also of older. Due to the popularity of computers they can be an important tool for learning physics concepts .young people through fun and interesting world of computers cannot just learn but to understand simple and complex concept of science. By using of technology features can be conducted experiments that cannot be done in real laboratories but even be conducted that not lead to fully understanding of science Learners interact with virtual objects but also each other and exchange their views not only in the micro world of a class but also with their peers all over the world and certainly they can learn from a distance without being in the classroom or in laboratory. In the present study we analyzed the most representative studies which have been carried out for utilization of Information and Communication Technology in education of physics. The results show that the use of technology is an excellent tool for the education of physics that leads to a deeper understanding of science. Confident to achieve the best possible results using of technology must be done in combination with a very good Curriculum which contains the traditional teaching. The role of teachers is significant which must guide with their knowledge their students and respond to their questions during the experiments with the using of computers. We signalize that are necessary and other studies for the optimization of these methods because for example the studies on digital games are still at the beginning as well as for the characteristics and the way of utili- 
zation of simulations, virtual reality and digital games in order to achieve the maximum of science learning.

\section{REFERENCES}

[1] Aleksandrova, A., \& Nancheva, N. Electromagnetism: interaction of simulation and real lab experiment. International Journal ITK vol. 1 Number 1 , pp. 44-50 (2007).

[2] Ferlin, E. P., Saavedra, N., da Cunha, J. C., \& Perretto, M.. Utilization of New Technologies in Science Teaching to Improve Student Learning at Engineering Introductory Physics Courses. Proc. of ICEE, Coimbra, Portugal. (2007)

[3] Farrokhnia, M. R., \& Esmailpour, A. A study on the impact of real, virtual and comprehensive experimenting on students' conceptual understanding of DC electric circuits and their skills in undergraduate electricity laboratory. Procedia-Social and Behavioral Sciences, 2(2), pp. 5474-5482 (2010) http://dx.doi.org/10.1016/j.sbspro.2010.03.893

[4] Kohnle, A., Baily, C., Hooley, C., \& Torrance, B. Optimization of simulations and activities for a new introductory quantum mechanics curriculum. arXiv preprint arXiv:1307.1483. (2013)

[5] Bozkurt, E., \& Ilik, A. The effect of computer simulations over students' beliefs on physics and physics success. Procedia-Social and Behavioral Sciences, 2(2), pp. 4587-4591 (2010) http://dx.doi.org/10.1016/j.sbspro.2010.03.735

[6] Zacharia, Z., \& Anderson, O. R. The effects of an interactive computer-based simulation prior to performing a laboratory inquiry-based experiment on students' conceptual understanding of physics. American Journal of Physics, 71(6), pp. 618-629 (2003) http://dx.doi.org/10.1119/1.1566427

[7] Podolefsky, N. S., Adams, W. K., \& Wieman, C. E. Student Choices when Learning with Computer Simulations. In 2009 PHYSICS EDUCATION RESEARCH CONFERENCE (Vol. 1179, No. 1, pp. 229-232 AIP Publishing. (2009)

[8] Aravind, V. R., \& Heard, J. W. Physics by simulation: Teaching circular motion using applets. Latin American Journal of Physics Education, 4(1), pp. 35-39 (2010)

[9] Kroothkaew, S., \& Srisawasdi, N. Teaching How Light can be Refracted Using Simulation-based Inquiry with a Dual-situated Learning Model. Procedia-Social and Behavioral Sciences, 93, pp. 2023-2027 (2013) http://dx.doi.org/10.1016/j.sbspro.2013.10.159

[10] Junglas, P. Teaching Thermodynamics using simulations. In 10th Baltic Region Seminar on Engineering Education, Szczecin, Poland pp. 4-6 (2006)

[11] Scheucher, B., Bailey, P. H., Gütl, C., \& Harward, J. V. Collaborative Virtual 3D Environment for Internet-Accessible Physics Experiments. iJOE, 5(S1), pp. 65-71 (2009)

[12] Taramopoulos A., Psillos D., Hatzikraniotis E., "Designing virtual experiments in electric circuits by high school students", 9th International Conference of the European Science Education Research Association (ESERA), Lyon, France, pp. 5-9. (2011)

[13] Kollöffel, B., \& Jong, T. Conceptual understanding of electrical circuits in secondary vocational engineering education: Combining traditional instruction with inquiry learning in a virtual lab. Journal of engineering education, 102(3), pp. 375-393. (2013). http://dx.doi.org/10.1002/jee.20022

[14] Chen, C. H., Yang, J. C., Shen, S., \& Jeng, M. C. A desktop virtual reality earth motion system in astronomy education. Journal of Educational Technology \& Society, 10(3), pp. 289-304. (2007).

[15] LOGOFĂTU, B., Munteanu, M., \& LOGOFĂTU, M. Studies on waves and oscillations with data acquisition systems. In Paper presented at the 5th International Balkan Workshop on Applied Physics (Vol. 5), pp. 13-19. (2004).

[16] Silva, L. F., Cardoso, A., Mendes, E. B., Takahashi, E. K., \& Martins, S. Associating non-immersive virtual reality and cognitive tools for Physics Teaching. In 9th International Conference on Engineering Education, San Juan, Puerto Rico. (2006).

[17] Yun, R., Pan, Z., \& Li, Y. An educational virtual environment for studying physics concept in high schools. In Advances in WebBased Learning-ICWL 2005 Volume 3583 of the series Lecture Notes in Computer Science pp. 326-331. Springer Berlin Heidelberg. (2005). http://dx.doi.org/10.1007/11528043_33
[18] McGrath, D., Wegener, M., McIntyre, T. J., Savage, C., \& Williamson, M. Student experiences of virtual reality: A case study in learning special relativity. American Journal of Physics, 78(8), pp. 862-868. (2010). http://dx.doi.org/10.1119/1.3431565

[19] Lee, H., Park, S. T., Kim, H. S., \& Lee, H. Students' understanding of astronomical concepts enhanced by an immersive Virtual Reality system (IVRS). In 3rd International Conference on Multimedia and Information and Communication Technologies in Education. (2005).

[20] Demaree, D., Stonebraker, S., Zhao, W., \& Bao, L. Virtual reality in introductory physics laboratories. In AIP Conference Proceedings (Vol. 790, p. 93). IOP INSTITUTE OF PHYSICS PUBLISHING LTD. (2005). http://dx.doi.org/10.1063/1.2084709

[21] Squire, K., Barnett, M., Grant, J. M., \& Higginbotham, T. Electromagnetism supercharged!: Learning physics with digital simulation games. In Proceedings of the 6th international conference on Learning sciences pp. 513-520). International Society of the Learning Sciences. (2004).

[22] Asbell-Clarke, J., Rowe, E., \& Sylvan, E. Working through impulse: assessment of emergent learning in a physics game. Games+Learning+Society 9.0 (GLS 9.0) Conference, Madison, WI. . (2013).

[23] Clark, D. B., Nelson, B. C., Chang, H. Y., Martinez-Garza, M., Slack, K., \& D'Angelo, C. M. Exploring Newtonian mechanics in a conceptually-integrated digital game: Comparison of learning and affective outcomes for students in Taiwan and the United States. Computers \& Education, 57(3), pp. 2178-2195 (2011). http://dx.doi.org/10.1016/j.compedu.2011.05.007

[24] Stapleton, A. J., \& Taylor, P. C. (2002). Physics and Playstation too: Learning physics with computer games. Science \& Mathematics Education Centre Curtin University of Technology, Perth. WA, 6845. Physics and Playstation too: Learning physics with computer games. Paper presented at the Australian Institute of Physics (AIP) conference. Retrieved July 18, 2003, from pctaylor.com/publications/aip2002/aip2002.htm (2002)

[25] Pittman C. Teaching With Portals: the Intersection of Video Games and Physics Education. LEARNing Landscapes | Vol. 6, No. 2, pp. 341-360 ( 2013)

[26] Carr, D., \& Bossomaier, T. Relativity in a rock field: A study of physics learning with a computer game. Australasian Journal of Educational Technology, 27(6), pp. 1042-1067 (2011). http://dx.doi.org/10.14742/ajet.928

[27] Johnson, C. I., \& Mayer, R. E. Applying the self-explanation principle to multimedia learning in a computer-based game-like environment. Computers in Human Behavior, 26(6) pp. 12461252 (2010). http://dx.doi.org/10.1016/j.chb.2010.03.025

[28] Holbert, N. R., \& Wilensky, U. (2011, June). Racing games for exploring kinematics: iu"; In Proceedings of the 7th international conference on Games+ Learning+ Society Conference pp. 109118 ETC Press. (2011)

[29] Masson, M. E., Bub, D. N., \& Lalonde, C. E. Video-game training and naïve reasoning about object motion. Applied Cognitive Psychology, 25(1), pp. 166-173 (2011) http://dx.doi.org/10.1002/acp. 1658

[30] Lee, L. H. J., \& Chee, Y. S. Generative conversations in gamebased learning. In Proceedings of the 9th international conference on Computer supported collaborative learning International Society of the Learning Sciences. Volume 1 pp. 419-428 (2009) http://dx.doi.org/10.3115/1600053.1600115

\section{AUTHORS}

Athanasios Drigas is a Research Director at IITN.C.S.R. Demokritos. He is the Coordinator of Telecoms Lab and founder of Net Media Lab since 1996. From 1990 to 1999 he was the Operational manager of the Greek Academic network. He has been the Coordinator of Several International Projects, in the fields of ICTs, and eservices (e-learning, e-psychology, e-government, einclusion, e-culture etc). He has published more than 270 articles, 7 books, 25 educational CD-ROMs and several patents. He has been a member of several International committees for the design and coordination of Network 
and ICT activities and of international conferences and journals. (e-mail: dr@iit.demokritos.gr).

Maria-Theofania Kontopoulou (graduate physicists) is physics professional. She has participated in various research projects regarding the use of Information and Communication Technologies (ICTs) in Physics teaching. She is also a scientific collaborator of N.C.S.R. DEMOKRITOS, Institute of Informatics and Telecommunications, Net Media Lab, Athens, Greece. (e-mail: mariairakleio@yahoo.gr)

Submitted 01 June 2016. Published as resubmitted by the authors 30 June 2016. 